\title{
Distance Dependence of Bidirectional Concerted Proton-Electron Transfer in Phenol-Ru(2,2'-bipyridine) ${ }_{3}{ }^{2+}$ Dyads
}

\author{
Jing Chen, ${ }^{\dagger[a]}$ Martin Kuss-Petermann, ${ }^{\dagger[a]}$ and Oliver S. Wenger**a]
}

\begin{abstract}
Proton-coupled electron transfer (PCET) was investigated in three covalent donor-bridge-acceptor molecules with different bridge lengths. Upon photoexcitation of their $\operatorname{Ru}(\text { bpy })_{3}{ }^{2+} \quad$ (bpy $=2,2^{\prime}$-bipyridine) photosensitizer in acetonitrile, intramolecular long-range electron transfer from a phenolic unit to $\mathrm{Ru}(\text { bpy })_{3}{ }^{2+}$ occurs in concert with release of the phenolic proton to pyrrolidine base. The kinetics of this bidirectional concerted proton-electron transfer (CPET) reaction were studied
\end{abstract}

as a function of phenol $-\mathrm{Ru}(\mathrm{bpy})_{3}{ }^{2+}$ distance by increasing the number of bridging $p$-xylene units. A distance decay constant $(\beta)$ of $0.67 \pm 0.23 \AA^{-1}$ was determined. The distance dependence of the rates for CPET is thus not significantly steeper than that for ordinary (i. e., not proton-coupled) electron transfer across the same bridges, despite the concerted motion of oppositely charged particles into different directions. Long-range bidirectional CPET is an important reaction in many proteins and plays a key role in photosynthesis; our results are relevant in the context of photoinduced separation of protons and electrons as a means of light-tochemical energy conversion. This is the first determination of $\beta$ for a bidirectional CPET reaction.

\section{Keywords: proton-coupled electron transfer $\bullet$ photochemistry time-resolved spectroscopy $\bullet$ molecular wire $\bullet$ hydrogen-bonding}

\section{Introduction}

The distance dependence of "simple" electron transfer has been thoroughly explored in proteins, ${ }^{1}$ DNA, ${ }^{2,}{ }^{3}$ self-assembled monolayers, ${ }^{4}$ and donor-bridge-acceptor molecules. ${ }^{5,}{ }^{6}$ An important open question is how the distance between an electron donor and an electron acceptor affects the rates of proton-coupled electron transfer (PCET) reactions, particularly when electron and proton transfer occur in concerted fashion and when the electron and the proton are transferred into different directions. Long-range PCET reactions of this type are biologically relevant, for instance in photosystem II, in ribonucleotide reductase, and in DNA. ${ }^{7-9}$ We are unaware of prior investigations of the distance dependence of bidirectional concerted proton-electron transfer (CPET) reactions.

The rate constant for a PCET reaction can be expressed in a similar way as the rate constant for "simple" electron transfer, i. e., in analogy to what is commonly known as the Marcus equation. ${ }^{10}$ In equation $1, \mathrm{H}_{\mathrm{AB}, \mathrm{PCET}}$ is the electronic coupling between the PCET reactant and product states, $\lambda_{\text {PCET }}$ is the reorganization energy associated with the overall PCET process, and $\triangle \mathrm{G}^{0}{ }_{\text {PCET }}$ is the reaction free energy. ${ }^{11}$ The interplay between these three factors governs the PCET rate constant ( $\left.\mathrm{k}_{\mathrm{PCET}}\right)$.

In many cases of "simple" electron transfer the distance dependence of reaction rates is dominated by the electronic coupling term $\left(\mathrm{H}_{\mathrm{AB}}\right),{ }^{1,5}$ but in other cases changes in reorganization energy $(\lambda)$ or reaction free energy $\left(\Delta G^{0}\right)$ with increasing donor-acceptor distance are more important. ${ }^{12,13}$ It is not a priori clear which one of the three factors $\left(\mathrm{H}_{\mathrm{AB}, \mathrm{PCET}}, \lambda_{\text {PCET }}, \Delta \mathrm{G}_{\text {PCET }}^{0}\right)$ will dominate the distance dependence of a bidirectional CPET reaction. On the one hand increasing the electron donor - electron acceptor distance is expected to have a significant influence on $\mathrm{H}_{\mathrm{AB}, \mathrm{PCET} .}{ }^{11}$ On the other hand it is known that bidirectional CPET reactions can be associated with significantly larger reorganization energies $\left(\lambda_{\mathrm{PCET}}\right)$ than "simple" electron transfer reactions, ${ }^{14}$ and significant changes in $\lambda_{\text {PCET }}$ with distance could strongly influence CPET rates.

$$
k_{P C E T}=\frac{2 \cdot \pi}{\hbar} \cdot H_{A B, P C E T}^{2} \cdot \sqrt{4 \cdot \pi \cdot \lambda_{P C E T} \cdot R \cdot T} \cdot \exp \left[\frac{\left(\Delta G_{P C E T}^{0}+\lambda_{P C E T}\right)^{2}}{4 \cdot \lambda_{P C E T} \cdot R \cdot T}\right]
$$

In the work presented herein we aimed to explore these basic apects by using the phenol- $\mathrm{Ru}(\mathrm{bpy})_{3}{ }^{2+}$ (bpy $=2,2$ '-bipyridine) dyads shown in Scheme 1. They are comprised of a phenolic unit acting as a combined electron-proton donor, $p$-xylene bridges of variable length, and a ruthenium photosensitizer as an electron acceptor. The proton acceptor is a base (pyrrolidine) which is added separately to the solution. Phenols have received much attention for mechanistic PCET studies, ${ }^{15-17}$ and there have been several investigations of donor-bridge-acceptor molecules incorporating phenols. ${ }^{18-24}$ Long-range PCET reactions have received increasing 
attention recently, ${ }^{24-28}$ but to our knowledge the dependence of the rates for bidirectional CPET on the electron donor - electron acceptor distance has never been investigated before. Given the biological relevance of this reaction type a systematic investigation of the model compounds from Scheme 1 seemed to be a worthy research endeavor.

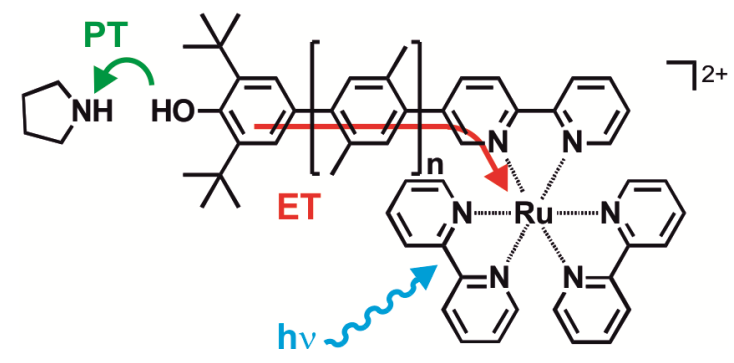

Scheme 1. Molecular structures of the $\mathrm{PhOH}-\mathrm{xy}_{\mathrm{n}}-\mathrm{Ru}^{2+}$ molecules $(\mathrm{n}=1-3)$ investigated in this work and illustration of their light-induced bidirectional CPET reaction involving pyrrolidine. $\mathrm{ET}=$ electron transfer, $\mathrm{PT}=$ proton transfer.

\section{Results and Discussion}

\section{Basic photochemistry and electrochemistry of the dyads}

In pure acetonitrile photoexcitation of the three dyads from Scheme 1 leads to ${ }^{3} \mathrm{MLCT}$ emission of the $\mathrm{Ru}(\mathrm{bpy})_{3}{ }^{2+}$ moieties, but there is no photochemistry. In absence of any base the ${ }^{3} \mathrm{MLCT}$ excited state lifetimes of the dyads are within experimental accuracy the same as for isolated $\mathrm{Ru}(\mathrm{bpy})_{3}{ }^{2+}$. Although a significantly better oxidant in the ${ }^{3}$ MLCT state than in the electronic ground state, $\mathrm{Ru}(\mathrm{bpy})_{3}{ }^{2+}$ is obviously not strongly oxidizing enough to convert the phenols to phenoxyl radical cations $\left(\mathrm{PhOH}^{+}\right)$. This finding can be understood on the basis of the electrochemical data in Table 1 which were extracted from cyclic voltammetry measurements (Figure S1). Reduction of $\mathrm{Ru}(\mathrm{bpy}){ }_{3}{ }^{2+}$ is ligand-based and occurs at ca. $-1.7 \mathrm{~V}$ vs. $\mathrm{Fc}^{+} / \mathrm{Fc}$ in $\mathrm{CH}_{3} \mathrm{CN}$ in all cases considered here. Oxidation of phenol $(\mathrm{PhOH})$ to phenoxyl radical cation $\left(\mathrm{PhOH}^{+}\right)$occurs at ca. $0.9 \mathrm{~V}$ vs. $\mathrm{Fc}^{+} / \mathrm{Fc}$ in the three dyads. Given a ${ }^{3} \mathrm{MLCT}$ energy $\left(\triangle \mathrm{E}_{\mathrm{MLCT}}\right)$ of 2.1 $\mathrm{eV},{ }^{29}$ one estimates a free energy of $\Delta \mathrm{G}_{\mathrm{ET} 1}^{0}=-e \cdot\left[E\left(\mathrm{bpy} / \mathrm{bpy}^{-}\right)+\right.$ $\left.\Delta \mathrm{E}_{\mathrm{MLCT}}-E\left(\mathrm{PhOH}^{+} / \mathrm{PhOH}\right)\right] \approx+0.5 \mathrm{eV}$ for photoinduced electron transfer. ${ }^{30}$ Such driving-force estimates are usually accurate to \pm 0.1 $\mathrm{eV}$. In the present case it seems safe to conclude that "simple" electron transfer from phenol to photoexcited $\mathrm{Ru}(\mathrm{bpy}){ }_{3}{ }^{2+}$ in pure $\mathrm{CH}_{3} \mathrm{CN}$ does not occur at measurable rates because it is too endergonic.

The situation changes completely when base is present because the neutral phenoxyl radical $(\mathrm{PhO} \bullet)$ instead of phenoxyl radical cation $\left(\mathrm{PhOH}^{+}\right)$can be formed upon photoexcitation of the $\mathrm{Ru}(\mathrm{bpy})_{3}{ }^{2+}$ photosensitizers. In other words, phenol oxidation becomes thermodynamically possible when combined with proton release (see below for driving-force estimates). In acetonitrile solution, addition of 4-aminopyridine quenches the ${ }^{3} \mathrm{MLCT}$ excited state of the $\mathrm{PhOH}-\mathrm{xy}_{1}-\mathrm{Ru}^{2+}$ dyad but has no effect on the longer congeners. The stronger base pyrrolidine leads to a photoreaction in all three dyads. We have therefore chosen pyrrolidine as a base for our PCET investigations. Importantly, up to concentrations of $1 \mathrm{M}$ in $\mathrm{CH}_{3} \mathrm{CN}$ pyrrolidine does not have any noticeable influence on the ${ }^{3}$ MLCT decay of the Ru(bpy) ${ }_{3}{ }^{2+}$ reference complex (Figure S2).

Table 1. Electrochemical potentials (in $\mathrm{V}$ vs. $\mathrm{Fc}^{+} / \mathrm{Fc}$ in $\mathrm{CH}_{3} \mathrm{CN}$ with $0.1 \mathrm{M} \mathrm{Bu}_{4} \mathrm{NPF}_{6}$ ) of the individual redox-active moieties of the dyads and some reference molecules.

\begin{tabular}{|c|c|c|c|c|}
\hline molecule & $\mathrm{Ru}^{\mathrm{III/II}}$ & bpy/bpy & $\mathrm{PhOH}^{+} / \mathrm{PhOH}$ & $\mathrm{PhO} \bullet / \mathrm{PhO}^{-}$ \\
\hline $\mathrm{PhOH}-\mathrm{xy}_{1}-\mathrm{Ru}^{2+}$ & 0.90 & -1.73 & 0.88 & -0.54 \\
\hline $\mathrm{PhOH}-\mathrm{xy}_{2}-\mathrm{Ru}^{2+}$ & 0.90 & -1.72 & 0.90 & -0.58 \\
\hline $\mathrm{PhOH}-\mathrm{xy}_{3}-\mathrm{Ru}^{2+}$ & 0.90 & -1.72 & 0.86 & -0.58 \\
\hline $\mathrm{Ru}(\mathrm{bpy})_{3}{ }^{2+}$ & 0.90 & -1.73 & & \\
\hline $2,4,6-{ }^{t} \mathrm{Bu}_{2} \mathrm{PhOH}$ & & & $1.18^{[\mathrm{a}]}$ & $-0.70^{[\mathrm{a}]}$ \\
\hline
\end{tabular}

These data were extracted from the cyclic voltammograms shown in Figure S1. [a] From ref. ${ }^{15}$.

(a)

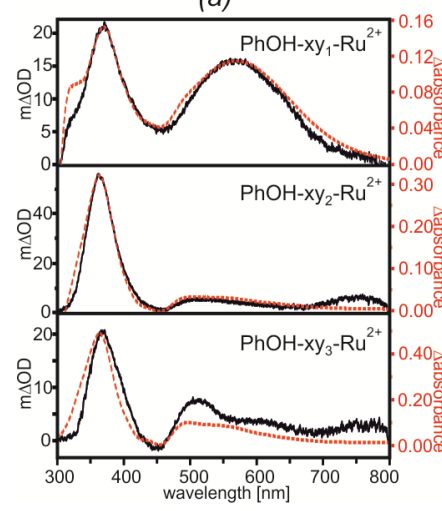

Figure 1. (a) Solid black lines: Transient absorption spectra measured after excitation of the three dyads in aerated $\mathrm{CH}_{3} \mathrm{CN}\left(2 \cdot 10^{5} \mathrm{M}\right)$ in presence of pyrrolidine at $532 \mathrm{~nm}$. Detection occurred by time-averaging over a period of $200 \mathrm{~ns}$ starting immediately after excitation with pulses of $\sim 10 \mathrm{~ns}$ duration. The pyrrolidine concentrations were: $25 \mathrm{mM}$ $\left(\mathrm{PhOH}-\mathrm{xy}_{1}-\mathrm{Ru}^{2+}\right), 96 \mathrm{mM}\left(\mathrm{PhOH}-\mathrm{xy}_{2}-\mathrm{Ru}^{2+}\right)$, and $3 \mathrm{M}\left(\mathrm{PhOH}-\mathrm{xy}_{3}-\mathrm{Ru}^{2+}\right)$. Dotted red traces: Difference spectra obtained by subtraction of the blue traces in Figure $1 \mathrm{~b}$ from the green traces in Figure 1b. (b) Solid blue traces: UV-Vis absorption of the dyads in pure $\mathrm{CH}_{3} \mathrm{CN}$. Dotted green traces: UV-Vis spectra of the deprotonated dyads in $\mathrm{CH}_{3} \mathrm{CN}$.

\section{Photochemistry in presence of pyrrolidine}

Transient absorption spectra of the three dyads in aerated $\mathrm{CH}_{3} \mathrm{CN}$ obtained in presence of excess pyrrolidine are shown in Figure 1a (solid black lines). These spectra were measured after selective excitation of the $\mathrm{Ru}(\mathrm{bpy})_{3}{ }^{2+}$ moieties at $532 \mathrm{~nm}$. The dyad concentrations were always $2 \cdot 10^{-5} \mathrm{M}$, but with increasing bridge length increasing pyrrolidine concentrations were necessary in order to induce efficient photochemistry. For $\mathrm{PhOH}-\mathrm{xy}_{1}-\mathrm{Ru}^{2+} \mathrm{a}$ pyrrolidine concentration of $25 \mathrm{mM}$ was sufficient whereas for $\mathrm{PhOH}-\mathrm{xy}_{2}-\mathrm{Ru}^{2+}$ and $\mathrm{PhOH}-\mathrm{xy}_{3}-\mathrm{Ru}^{2+}$ concentrations of $96 \mathrm{mM}$ and 3 $\mathrm{M}$, respectively, were employed. Under these conditions conversion to the photoproducts was essentially complete after the $\sim 10 \mathrm{~ns}$ duration of the laser excitation pulses in all three cases. Measurement of the transient absorption data in Figure 1a occurred by time integration over a period of $200 \mathrm{~ns}$. The three resulting spectra are relatively similar to each other and feature a prominent band near $365 \mathrm{~nm}$ in addition to weaker bands at longer wavelengths. The shape of the transient absorption spectra can be understood readily on the basis of the UV-Vis data shown in Figure 1b. The 
solid blue traces in Figure $1 \mathrm{~b}$ are the absorption spectra of the $\mathrm{PhOH}-\mathrm{xy}_{\mathrm{n}}-\mathrm{Ru}^{2+}$ dyads in pure $\mathrm{CH}_{3} \mathrm{CN}$, whereas the dashed green traces are the absorption spectra of their deprotonated forms $\left(\mathrm{PhO}^{-}-\right.$ $\left.\mathrm{xy}_{\mathrm{n}}-\mathrm{Ru}^{2+}\right)$. Deprotonation occurred by addition of excess tetrabutylammonium hydroxide to the $\mathrm{CH}_{3} \mathrm{CN}$ solutions. When subtracting the solid blue traces from the dashed green traces in Figure $1 \mathrm{~b}$, one obtains the difference spectra shown as dotted red traces in Figure 1a. The similarity between these derived difference spectra and the experimental transient absorption spectra (solid black lines in Figure 1a) is evident, and we conclude that the photoproducts which are detected on the nanosecond timescale are comprised of the deprotonated phenols and $\mathrm{Ru}(\mathrm{bpy})_{3}{ }^{2+}$ in the electronic ground state. It is as if the three dyads from Scheme 1 merely acted as photoacids.

However, excitation at $532 \mathrm{~nm}$ occurs selectively into the $\mathrm{Ru}(\text { bpy })_{3}{ }^{2+}$ moieties. The phenols have insignificant extinction at this wavelength, and it is not obvious why the phenolic units should become more acidic upon excitation of the $\mathrm{Ru}(\mathrm{bpy}){ }_{3}{ }^{2+}$ moieties which are more than $12 \AA$ away. However, the apparent photoacid behavior can be explained by a reaction sequence of concerted proton-electron transfer (CPET) followed by "simple" electron transfer (back-ET) in the reverse direction (Scheme 2). ${ }^{31}$ In order to understand this reaction sequence it is necessary to work out the thermodynamics of the different photochemical reaction pathways for the $\mathrm{PhOH}-\mathrm{xy}_{\mathrm{n}}-\mathrm{Ru}^{2+}$ dyads in presence of pyrrolidine (pyr).

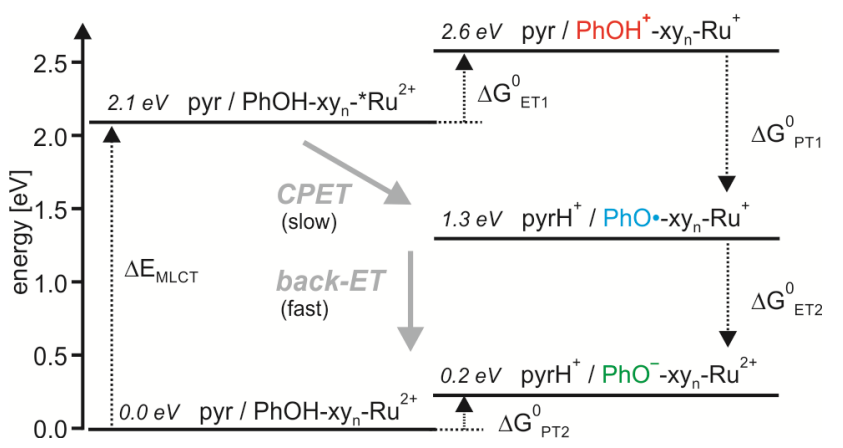

Scheme 2. Energy-level diagram established on the basis of the electrochemical potentials in Table 1 and the acidity constants in Table 2; see supporting information for details.

The starting point in the energy-level diagram of Scheme 2 is the ${ }^{3} \mathrm{MLCT}$ state $2.1 \mathrm{eV}$ above the ground state. ${ }^{29}$ As discussed above, "simple" photoinduced electron transfer to produce phenoxyl radical cations and reduced ruthenium complex (pyr / $\mathrm{PhOH}^{+}-\mathrm{xy}_{\mathrm{n}}-$ $\mathrm{Ru}^{+}$state at $2.6 \mathrm{eV}$ ) is endergonic by $0.5 \mathrm{eV}$. The absence of any photochemical reaction in pure $\mathrm{CH}_{3} \mathrm{CN}$ without base strongly suggests that the pyr / $\mathrm{PhOH}^{+}-\mathrm{xy}_{\mathrm{n}}-\mathrm{Ru}^{+}$photoproduct is never formed, not even as a short-lived intermediate when base is present. However, on the basis of equation 2 photoinduced CPET producing protonated pyrrolidine $\left(\mathrm{pyrH}^{+}\right)$, phenoxyl radical $(\mathrm{PhO} \bullet)$, and reduced ruthenium complex $\left(\mathrm{Ru}^{+}\right)$is estimated to be exergonic by approximately $0.8 \mathrm{eV}$.

$\Delta \mathrm{G}_{\mathrm{PT} 1}^{0}=0.059 \mathrm{eV} \cdot\left[\mathrm{pK}_{\mathrm{a}}\left(\mathrm{PhOH}^{+}\right)-\mathrm{pK}_{\mathrm{a}}\left(\mathrm{pyrH}^{+}\right)\right]$

Specifically, equation 2 is used to estimate the free energy associated with protonation of pyrrolidine by phenoxyl radical cation. ${ }^{32}$ The $\mathrm{pK}_{\mathrm{a}}$ of $\mathrm{PhOH}^{+}$in $\mathrm{CH}_{3} \mathrm{CN}$ is -3 and the $\mathrm{pK}_{\mathrm{a}}$ of the conjugate acid of pyrrolidine $\left(\mathrm{pyrH}^{+}\right)$in $\mathrm{CH}_{3} \mathrm{CN}$ is 19.56 (Table 2), ${ }^{15,}{ }^{33}$ resulting in $\Delta \mathrm{G}_{\mathrm{PT} 1}^{0} \approx-1.3 \mathrm{eV}$. Consequently, the $\mathrm{pyrH}^{+}$/
$\mathrm{PhO} \bullet-\mathrm{xy}_{\mathrm{n}}-\mathrm{Ru}^{+}$state must be approximately $1.3 \mathrm{eV}$ below the pyr / $\mathrm{PhOH}^{+}-\mathrm{xy}_{\mathrm{n}}-\mathrm{Ru}^{+}$state, i. e., at $2.6 \mathrm{eV}-1.3 \mathrm{eV}=1.3 \mathrm{eV}$. This is 0.8 $\mathrm{eV}$ below the initially populated ${ }^{3} \mathrm{MLCT}$ state. Thus, the CPET reaction in which phenol oxidation by photoexcited $\mathrm{Ru}(\mathrm{bpy})_{3}{ }^{2+}$ occurs in concert with release of the phenolic proton to pyrrolidine (arrow marked with "CPET" in Scheme 2) has $\Delta \mathrm{G}_{\text {CPET }}^{0}=-0.8 \mathrm{eV}$. It seems reasonable to conclude that this is indeed the first reaction step occurring after photoexcitation.

Table 2. Acidity constants in $\mathrm{CH}_{3} \mathrm{CN}$.

\begin{tabular}{ll}
\hline acid & $\mathrm{pK}_{\mathrm{a}}$ \\
\hline $\mathrm{pyrH}^{+}$ & $19.56^{[\mathrm{a}]}$ \\
$\mathrm{PhOH}$ & $28^{[\mathrm{b}]}$ \\
$\mathrm{PhOH}^{+}$ & $-3^{[\mathrm{b}]}$ \\
\hline
\end{tabular}

[a] From ref. ${ }^{33}$. [b] Values for $2,4,6-{ }^{t} \mathrm{Bu} 3 \mathrm{PhOH}$ from ref. ${ }^{15}$.

The pyrH $^{+} / \mathrm{PhO} \bullet-\mathrm{xy}_{\mathrm{n}}-\mathrm{Ru}^{+}$photoproduct at $1.3 \mathrm{eV}$ is comprised of a strongly reducing ruthenium complex $\left(\mathrm{Ru}(\mathrm{bpy})_{3}{ }^{+}\right)$connected to a relatively good electron acceptor (PhO•). Using equation 3 one can estimate the reaction free energy associated with intramolecular electron transfer from $\mathrm{Ru}(\mathrm{bpy})_{3}{ }^{+}$to $\mathrm{PhO} \bullet$.

$\Delta \mathrm{G}_{\mathrm{ET} 2}^{0}=-e \cdot\left[E\left(\mathrm{PhO} \bullet / \mathrm{PhO}^{-}\right)-E\left(\mathrm{bpy} / \mathrm{bpy}^{-}\right)\right]$

With the electrochemical potentials in Table 1 equation 3 yields $\Delta \mathrm{G}_{\mathrm{ET} 2}^{0} \approx-1.1 \mathrm{eV}$. In other words, after initial CPET thermal electron transfer from $\mathrm{Ru}(\mathrm{bpy})_{3}{ }^{+}$to $\mathrm{PhO} \bullet$ is exergonic by $1.1 \mathrm{eV}$. This second reaction step (downward arrow in Scheme 2 labeled "back-ET") leads to the photoproducts which are detected by transient absorption spectroscopy in Figure 1a, i. e., to $\mathrm{Ru}(\mathrm{bpy})_{3}{ }^{2+}$ in the ground state and phenolate. Using the thermodynamic cycle described above, one arrives at the conclusion that the $\mathrm{pyrH}^{+} / \mathrm{PhO}^{-}-\mathrm{xy}_{\mathrm{n}}-\mathrm{Ru}^{2+}$ state is approximately $0.2 \mathrm{eV}$ above the ground state. Alternatively, using the $\mathrm{pK}_{\mathrm{a}}$ values of phenol $(28)^{15}$ and the conjugate acid of pyrrolidine $(19.56)^{33}$ in $\mathrm{CH}_{3} \mathrm{CN}$ one arrives at the conclusion that the respective state is $0.5 \mathrm{eV}$ above the ground state $\left(\Delta \mathrm{G}_{\mathrm{PT} 2}^{0}\right)$. The deviation between the two energy estimates for the same state $(0.2 \mathrm{eV}$ vs. $0.5 \mathrm{eV})$ simply reflects the approximate character of these thermodynamic considerations and the uncertainty in the electrochemical potentials and acidity constants. We assume that our $\Delta \mathrm{G}_{\mathrm{ET}}^{0}$ estimates are accurate to $\pm 0.1 \mathrm{eV}$ while the $\Delta \mathrm{G}_{\mathrm{PT}}^{0}$ estimates are associated with errors of $\pm 0.3 \mathrm{eV}$.

The conclusion from this section is that the apparent photoacid behavior of the three dyads in presence of pyrrolidine is due to a sequence of two consecutive reaction steps: Photoinduced CPET followed by electron transfer in the reverse direction (two thick grey arrows in Scheme 2). ${ }^{31}$ The $\mathrm{pyrH}^{+} / \mathrm{PhO} \bullet-\mathrm{xy}_{\mathrm{n}}-\mathrm{Ru}^{+}$intermediate (at $1.3 \mathrm{eV}$ ) produced after initial CPET escapes detection because it decays more rapidly than it is formed. ${ }^{34}$ In other words, CPET is the rate-determining step leading to the observable $\mathrm{pyrH}^{+} / \mathrm{PhO}^{-}-\mathrm{xy}_{\mathrm{n}}{ }^{-}$ $\mathrm{Ru}^{2+}$ photoproducts. This view is consistent with previously reported rates exceeding $10^{9} \mathrm{~s}^{-1}$ for "simple" electron transfer over three adjacent $p$-phenylene units as well as with the relative 
sluggishness of CPET reactions in related phenol-Ru(bpy $)_{3}{ }^{3+}$ and phenol-rhenium(I) systems. ${ }^{14,} 23,24,35-38$ Some of the H/D kinetic isotope effects reported below provide additional support for the conclusion that CPET is rate-determining.

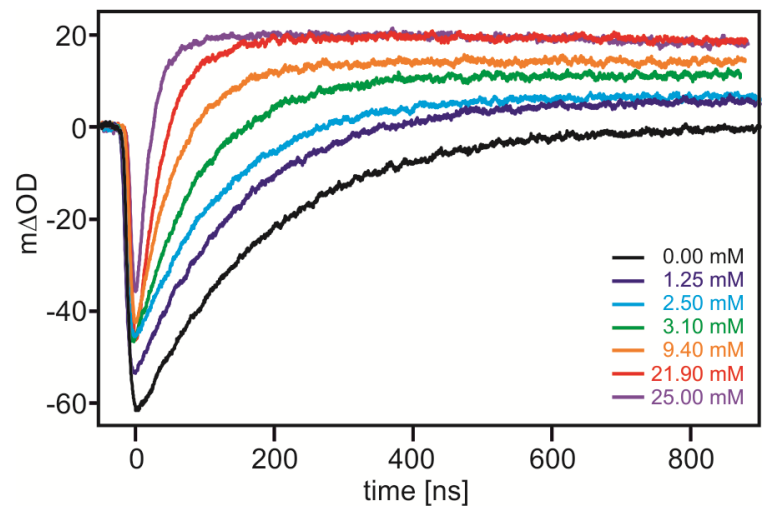

Figure 2. Temporal evolution of the transient absorption signal of $\mathrm{PhOH}-\mathrm{xy}_{1}-\mathrm{Ru}^{2+}\left(2 \cdot 10^{5}\right.$ M) in aerated $\mathrm{CH}_{3} \mathrm{CN}$ at $450 \mathrm{~nm}$ after excitation at $532 \mathrm{~nm}$ with pulses of $\sim 10 \mathrm{~ns}$ duration. Pyrrolidine concentrations are given in the inset.

\section{Kinetics of the photoreaction in presence of pyrrolidine}

In order for the photoinduced CPET reaction to occur, pyrrolidine must be in immediate proximity to the phenolic units because the proton cannot tunnel very far. ${ }^{39}$ It is therefore reasonable to expect CPET to occur predominantly from the hydrogen-bonded encounter adducts on the right-hand side of the chemical equilibrium in equation 4 , in analogy to prior studies of PCET with hydrogen-bonded phenols. ${ }^{22,31,39-46}$

pyr $+\mathrm{PhOH}-\mathrm{xy}_{\mathrm{n}}-\mathrm{Ru}^{2+} \leftrightarrows \mathrm{pyr}^{\cdots} \cdot \mathrm{PhOH}-\mathrm{xy}_{\mathrm{n}}-\mathrm{Ru}^{2+}$

Any analysis of the CPET kinetics must take this equilibrium into account. The CPET kinetics of the three dyads can be measured by monitoring the transient absorption signal at $450 \mathrm{~nm}$ as a function of time after excitation at $532 \mathrm{~nm}$ with laser pulses of $\sim 10 \mathrm{~ns}$ width. Exemplary bleach recoveries for the $\mathrm{PhOH}-\mathrm{xy}_{1}-\mathrm{Ru}^{2+}$ dyad are shown in Figure 2, all others are reported in Figure S3. Immediately after the laser pulses one detects a bleach at $450 \mathrm{~nm}$ due to the disappearance of the ${ }^{1}$ MLCT absorption as a consequence of $\mathrm{Ru}(\mathrm{bpy})_{3}{ }^{2+}$ excitation. ${ }^{47}$ In absence of pyrrolidine the bleach recovery time is $\sim 200 \mathrm{~ns}$ in aerated $\mathrm{CH}_{3} \mathrm{CN}$ for all three dyads, corresponding to relaxation of the ${ }^{3} \mathrm{MLCT}$ state to the ground state like in free $\mathrm{Ru}(\mathrm{bpy})_{3}{ }^{2+}$. In presence of pyrrolidine the bleach recovery becomes significantly more rapid (Figure 2, Figure S3) due to the sequence of photoreactions (CPET, back-ET) discussed in the previous paragraph. Since the CPET step is rate-determining, these bleach recovery times essentially reflect the kinetics of the CPET reaction.

The observed rate constants $\left(\mathrm{k}_{\mathrm{obs}}\right.$, extracted from single exponential fits to the data in Figure 2 and Figure S3) are plotted as a function of pyrrolidine concentration in Figure 3. Squares, circles and triangles are used to visually set apart data for dyads with 1,2 , and $3 p$-xylene spacers; open symbols represent data for ordinary dyads, filled symbols represent data obtained for their deuterated analogs in presence of deuterated pyrrolidine. In this context "deuterated" means replacement of the phenolic proton by a deuteron and replacement of the easily exchangeable N-H proton of pyrrolidine by a deuteron. The most important observation is that upon bridge lengthening increasing pyrrolidine concentrations are necessary to induce similar reaction kinetics. This is a manifestation of the fact that the CPET reaction rate decreases with increasing bridge length. The experimentally determined bleach recovery rate constants $\left(\mathrm{k}_{\mathrm{obs}}\right)$ are principally a function of the intrinsic ${ }^{3} \mathrm{MLCT}$ excited-state decay rate constant $\left(\mathrm{k}_{0}\right)$ and the rate constant for CPET $\left(\mathrm{k}_{\mathrm{CPET}}\right)$. Equation 5 further contains a rate constant for "simple" electron transfer $\left(\mathrm{k}_{\mathrm{ET}}\right)$ and a $\mathrm{k}_{\mathrm{Q}} \cdot$ [base] term describing direct ${ }^{3} \mathrm{MLCT}$ excited-state quenching by the base..$^{22,40,41}$

$k_{o b s}=k_{0}+k_{E T}+k_{Q} \cdot[$ base $]+k_{C P E T} \cdot \frac{K_{A} \cdot[\text { base }]}{1+K_{A} \cdot[\text { base }]}$

As discussed above, in absence of pyrrolidine the ${ }^{3} \mathrm{MLCT}$ lifetime of the three dyads in aerated $\mathrm{CH}_{3} \mathrm{CN}$ is within experimental accuracy the same as that of isolated $\mathrm{Ru}(\mathrm{bpy})_{3}{ }^{2+}$ hence we conclude that $\mathrm{k}_{\mathrm{ET}}$ is negligible compared to $\mathrm{k}_{0}$. Addition of up to $1 \mathrm{M}$ pyrrolidine to a $2 \cdot 10^{-5} \mathrm{M}$ solution of $\mathrm{Ru}(\mathrm{bpy})_{3}{ }^{2+}$ in aerated $\mathrm{CH}_{3} \mathrm{CN}$ has no influence on the ${ }^{3} \mathrm{MLCT}$ emission and its lifetime (Figure S2) From this we conclude that $\mathrm{k}_{\mathrm{Q}} \leq 10^{5} \mathrm{M}^{-1} \mathrm{~s}^{-1}$. Fits with equation 5 to the experimental data in Figure 3 are therefore possible with only two adjustable parameters: The CPET rate constant $\left(\mathrm{k}_{\mathrm{CPET}}\right)$ and the association constant $\left(\mathrm{K}_{\mathrm{A}}\right)$ describing the chemical equilibrium in equation 4 . We attempted to determine $\mathrm{K}_{\mathrm{A}}$ independently on the basis of steady-state luminescence data as described previously (Figure S4, Figure S5) but have not been able to extract meaningful $\mathrm{K}_{\mathrm{A}}$ values from this procedure (see supporting information). ${ }^{49}$



Figure 3. Experimentally observable ${ }^{3}$ MLCT-depopulation rate constants ( $k_{\text {obs }}$ ) as a function of pyrrolidine concentration for the three dyads and their deuterated analogs. The actual experimental data are shown in Figure 2 and Figure S3. The solid lines are fits to the experimental data with equation 5 as described in the text. Results from these fits are reported in Table 3.

Two-parameter fits to single sets of data from Figure 3 turned out to be not meaningful, ${ }^{50}$ and therefore we decided to fit all six data sets globally with the restriction to one common $\mathrm{K}_{\mathrm{A}}$ value for all six cases. In other words, we assume that the equilibrium in equation 4 is affected neither by the number of $p$-xylene spacers nor by deuteration. Our fits employed $\mathrm{k}_{0}=5.2 \cdot 10^{6} \mathrm{~s}^{-1}, \mathrm{k}_{\mathrm{ET}}=0 \mathrm{~s}^{-1}$, and $\mathrm{k}_{\mathrm{Q}}=$ $10^{5} \mathrm{M}^{-1} \mathrm{~s}^{-1}$ as non-adjustable parameters and produced the $\mathrm{k}_{\mathrm{CPET}}$ values reported in the third column of Table 3 and $\mathrm{K}_{\mathrm{A}}=1.4 \pm 0.2 \mathrm{M}^{-1}$ The fits are shown as solid lines in Figure 3. 
A value of $1.4 \pm 0.2 \mathrm{M}^{-1}$ for $\mathrm{K}_{\mathrm{A}}$ is in line with previously reported equilibrium constants of hydrogen-bonded phenols in benzonitrile. $^{40,41}$ The H/D kinetic isotope effect (KIE) of $3.91 \pm 0.95$ (ratio between $\mathrm{k}_{\mathrm{CPET}}$ of $\mathrm{PhOH}-\mathrm{xy}_{2}-\mathrm{Ru}^{2+}$ and PhOD$\mathrm{xy}_{2}-\mathrm{Ru}^{2+}$ ) found for the dyad with two $p$-xylene bridging units is significant and supports the hypothesis of a rate-determining CPET step. The two other dyads exhibit smaller KIEs $\left(1.26 \pm 0.40, \mathrm{xy}_{1}\right.$ system $)$ and $\left(0.95 \pm 0.44, \mathrm{xy}_{3}\right.$ system $)$, but the absence of a significant KIE is not an argument against CPET. $^{48}$ Trends in the magnitudes of KIEs associated with PCETs are generally difficult to rationalize because the KIE depends on many different parameters. ${ }^{11}$

Table 3. CPET rate constants $\left(\mathrm{k}_{\mathrm{CPET}}\right)$ as a function of phenol-ruthenium (center-tocenter) distance $\left(\mathrm{R}_{\mathrm{DA}}\right)$.

\begin{tabular}{lcc}
\hline molecule & $\mathrm{R}_{\mathrm{DA}}[\AA]$ & $\mathrm{k}_{\mathrm{CPET}}\left[\mathrm{s}^{-1}\right]$ \\
\hline $\mathrm{PhOH}-\mathrm{xy}_{1}-\mathrm{Ru}^{2+}$ & 12.2 & $(1.07 \pm 0.14) \cdot 10^{9}$ \\
$\mathrm{PhOH}-\mathrm{xy}_{1}-\mathrm{Ru}^{2+}$ & 12.2 & $(0.85 \pm 0.12) \cdot 10^{9}$ \\
$\mathrm{PhOH}-\mathrm{xy}_{2}-\mathrm{Ru}^{2+}$ & 16.5 & $(3.35 \pm 0.41) \cdot 10^{8}$ \\
$\mathrm{PhOH}-\mathrm{xy}_{2}-\mathrm{Ru}^{2+}$ & 16.5 & $(0.86 \pm 0.10) \cdot 10^{8}$ \\
$\mathrm{PhOH}-\mathrm{xy}_{3}-\mathrm{Ru}^{2+}$ & 20.8 & $(3.41 \pm 1.22) \cdot 10^{6}$ \\
$\mathrm{PhOH}-\mathrm{xy}_{3}-\mathrm{Ru}^{2+}$ & 20.8 & $(3.58 \pm 1.14) \cdot 10^{6}$ \\
\hline
\end{tabular}

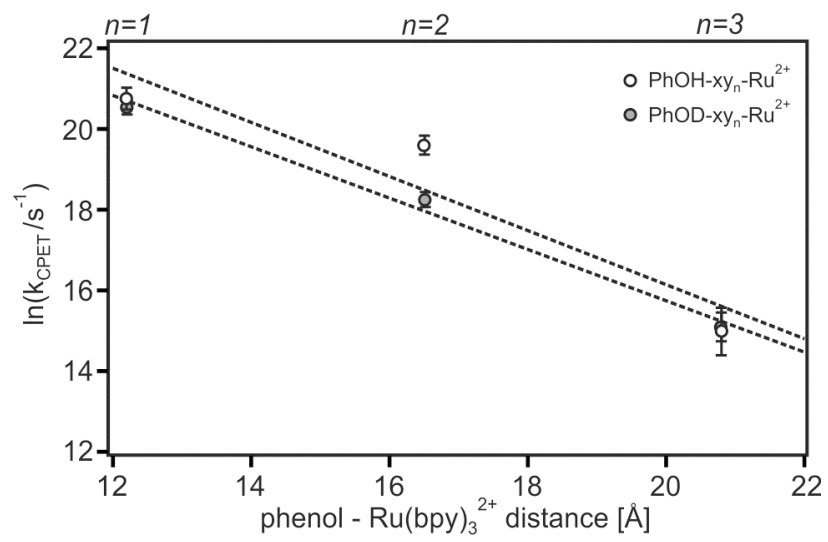

Figure 4. Distance dependence of kсPEт. The solid lines are linear regression fits yielding the $\beta$-values reported in the text.

The distance dependence of the CPET rate constants is shown in Figure 4 in semilogarithmic representation; $R_{D A}$ corresponds to center-to-center distances between the phenol and $\mathrm{Ru}(\mathrm{bpy})_{3}{ }^{2+}$ moieties as obtained by molecular modeling. Linear regression fits to the data in Figure 4 yields distance decay constants $(\beta)$ of $0.67 \pm 0.23 \AA^{-1}$ and $0.64 \pm 0.06 \AA^{-1}$ for the $\mathrm{PhOH}-\mathrm{xy}_{\mathrm{n}}-\mathrm{Ru}^{2+}$ and PhOD- $\mathrm{xy}_{\mathrm{n}}-\mathrm{Ru}^{2+}$ series, respectively. These $\beta$-values are much in line with those extracted for "simple" (i. e., not proton-coupled) electron tunneling across oligo- $p$ xylene spacers $\left(0.77 \AA^{-1}, 0.52 \AA^{-1}\right)^{51,52}$ and oligo- $p$-phenylene bridges. ${ }^{35,36,53,54}$ Extrapolation of these exponential fits to vander-Waals contact distance between phenol and $\mathrm{Ru}(\mathrm{bpy})_{3}{ }^{2+}$ reactants $\left(\mathrm{R}_{\mathrm{DA}}=4 \AA\right)$ yields $\mathrm{k}_{\mathrm{CPET}}=4.5 \cdot 10^{11} \mathrm{~s}^{-1}$ for ordinary phenol and $\mathrm{k}_{\text {CPET }}=1.8 \cdot 10^{11} \mathrm{~s}^{-1}$ for deuterated phenol. These rates compare favorably to those of "simple" electron transfer between reactants in van-der-Waals contact. ${ }^{1,10}$

\section{Conclusion}

The distance dependence of the rates for bidirectional CPET in the systems investigated here does not deviate drastically from that of ordinary (i. e., not proton-coupled) electron transfer. The dominant contribution to this distance dependence likely comes from $\mathrm{H}_{\mathrm{AB} \text {,PCET }}$ (eq. 1) which can be described as a product of electronic coupling matrix elements for the electron transfer $\left(\mathrm{H}_{\mathrm{AB}, \mathrm{ET}}\right)$ and proton transfer components $\left(\mathrm{H}_{\mathrm{AB}, \mathrm{PT}}\right)$ of the overall CPET reaction. ${ }^{11,39}$ Increasing the electron transfer distance decreases $\mathrm{H}_{\mathrm{AB}, \mathrm{ET}}$ whereas $\mathrm{H}_{\mathrm{AB}, \mathrm{PT}}$ remains constant. From this perspective the observed similarity between the distance dependences of bidirectional CPET $\left(\beta=0.67 \pm 0.23 \AA^{-}\right.$ $\left.{ }^{1}\right)$ and ordinary electron transfer $\left(\beta=0.52-0.77 \AA^{-1}\right)^{51,52,55}$ across the same type of bridges is readily understandable. Changes in reorganization energy $\left(\lambda_{\mathrm{PCET}}\right.$, eq. 1$)$ with increasing electron donor - electron acceptor distance appear to be relatively minor. It is possible that reorganization energy effects are responsible for the deviation from the exponential distance dependence of CPET rates observed here. ${ }^{12}$

Since this is the first determination of $\beta$ for a bidirectional CPET reaction it is delicate to make a general statement, but it seems that the dependence of rates for bidirectional CPET on electron donor - electron acceptor distance is not steeper than that of ordinary electron transfer rates, despite the concerted motion of oppositely charged particles into different directions. This finding is of key importance when attempting to perform light-driven separation of electrons and protons in order to build up charge gradients across natural or artificial membranes, similar to what occurs in photosystem II. We find that a long electron transfer distance (up to $\sim 20 \AA$ ) is no obstacle to bidirectional CPET.

\section{Experimental Section}

${ }^{1} \mathrm{H}$ NMR spectra were measured on a $400 \mathrm{MHz}$ Bruker Avance instrument. The ${ }^{1} \mathrm{H}$ spectra were referenced relative to tetramethylsilane by using the solvent signals as internal standards. High-resolution mass spectra were recorded on a Finnigan MAT8200 mass spectrometer. Elemental analysis was performed using a Vario EL III CHNS analyzer from Elementar. For cyclic voltammetry a Versastat3-200 potentiostat from Princeton Applied Research was used, and a glassy carbon disk served as a working electrode. A silver wire was used as a counter-electode, and a second silver wire was employed as a quasi-reference electrode. Proper referencing of the potentials occurred through addition of small amounts of ferrocene and by recording of the ferrocenium / ferrocene redox wave. Voltage sweeps were performed with rates of $100 \mathrm{mV} / \mathrm{s}$. Optical absorption spectra were recorded on a Shimadzu UV-1800 instrument. Steady-state luminescence was measured on a Fluorolog322 instrument from Horiba Jobin-Yvon. Transient absorption was performed with an LP920-KS spectrometer from Edinburgh Instruments, equipped with an R928 photomultiplier and an iCCD camera from Andor. The frequency-doubled output from a Quantel Brilliant b laser was used as an excitation source. The duration of the laser excitation pulses was approximately $10 \mathrm{~ns}$. Transient absorption spectra were generally recorded by time-averaging the signal over a detection period of $200 \mathrm{~ns}$. Quartz cuvettes from Starna were employed for all optical spectroscopic experiments. For H/D kinetic isotope effect studies, the deuterated dyads were dissolved in pure $\mathrm{CH}_{3} \mathrm{CN}$ and deuterated pyrrolidine was added. Synthetic protocols and product characterization data are given in the Supporting Information.

\section{Acknowledgements}


This work was supported by the Swiss National Science Foundation (grant number 200021_146231/1) and by the Deutsche Forschungsgemeinschaft (IRTG-1422).

[1] H. B. Gray, J. R. Winkler, Proc. Natl. Acad. Sci. U. S. A. 2005, 102,3534 .

[2] B. Giese, Annu. Rev. Biochem. 2002, 71, 51.

[3] J. C. Genereux, J. K. Barton, Chem. Rev. 2010, 110, 1642.

[4] H. J. Yoon, N. D. Shapiro, K. M. Park, M. M. Thuo, S. Soh, G. M. Whitesides, Angew. Chem. Int. Ed. 2012, 51, 4658.

[5] V. Balzani, Electron transfer in chemistry, VCH Wiley, Weinheim, 2001.

[6] P. P. Edwards, H. B. Gray, M. T. J. Lodge, R. J. P. Williams, Angew. Chem. Int. Ed. 2008, 47, 6758.

[7] B. A. Barry, G. T. Babcock, Proc. Natl. Acad. Sci. U. S. A. 1987 $84,7099$.

[8] E. C. Minnihan, D. G. Nocera, J. Stubbe, Acc. Chem. Res. 2013, doi: 10.1021/ar4000407.

[9] A. Kumar, M. D. Sevilla, Chem. Rev. 2010, 110, 7002.

[10] R. A. Marcus, N. Sutin, Biochim. Biophys. Acta 1985, 811, 265.

[11] S. Hammes-Schiffer, A. A. Stuchebrukhov, Chem. Rev. 2010, 110, 6939.

[12] B. S. Brunschwig, S. Ehrenson, N. Sutin, J. Am. Chem. Soc. 1984, 106,6858 .

[13] S. S. Isied, A. Vassilian, J. F. Wishart, C. Creutz, H. A. Schwarz, N. Sutin, J. Am. Chem. Soc. 1988, 110, 635.

[14] M. Sjödin, S. Styring, B. Åkermark, L. C. Sun, L. Hammarström, J. Am. Chem. Soc. 2000, 122, 3932.

[15] J. J. Warren, T. A. Tronic, J. M. Mayer, Chem. Rev. 2010, 110, 6961.

[16] D. R. Weinberg, C. J. Gagliardi, J. F. Hull, C. F. Murphy, C. A. Kent, B. C. Westlake, A. Paul, D. H. Ess, D. G. McCafferty, T. J. Meyer, Chem. Rev. 2012, 112, 4016.

[17] C. Costentin, M. Robert, J.-M. Savéant, Acc. Chem. Res. 2010, 43 1019.

[18] T. Irebo, M.-T. Zhang, T. F. Markle, A. M. Scott, L. Hammarström, J. Am. Chem. Soc. 2012, 134, 16247.

[19] M. Sjödin, T. Irebo, J. E. Utas, J. Lind, G. Merenyi, B. Åkermark, L. Hammarström, J. Am. Chem. Soc. 2006, 128, 13076.

[20] L. C. Sun, M. Burkitt, M. Tamm, M. K. Raymond, M. Abrahamsson, D. LeGourriérec, Y. Frapart, A. Magnuson, P. H. Kenéz, P. Brandt, A. Tran, L. Hammarström, S. Styring, B. Åkermark, J. Am. Chem. Soc. 1999, 121, 6834.

[21] T. Lachaud, A. Quaranta, Y. Pellegrin, P. Dorlet, M. F. Charlot, S. Un, W. Leibl, A. Aukauloo, Angew. Chem. Int. Ed. 2005, 44, 1536.

[22] A. A. Pizano, J. L. Yang, D. G. Nocera, Chem. Sci. 2012, 3, 2457.

[23] T. Irebo, S. Y. Reece, M. Sjödin, D. G. Nocera, L. Hammarström, J. Am. Chem. Soc. 2007, 129, 15462.

[24] M. Kuss-Petermann, H. Wolf, D. Stalke, O. S. Wenger, J. Am Chem. Soc. 2012, 134, 12844.

[25] O. S. Wenger, Acc. Chem. Res. 2013, 46, 1517.

[26] V. W. Manner, A. G. DiPasquale, J. M. Mayer, J. Am. Chem. Soc. 2008, 130, 7210

[27] V. W. Manner, J. M. Mayer, J. Am. Chem. Soc. 2009, 131, 9874.

[28] J. J. Warren, A. R. Menzeleev, J. S. Kretchmer, T. F. Miller, H. B. Gray, J. M. Mayer, J. Phys. Chem. Lett. 2013, 4, 519.
[29] D. M. Roundhill, Photochemistry and Photophysics of Metal Complexes, Plenum Press, New York, 1994.

[30] A. Weller, Z. Phys. Chem. 1982, 133, 93.

[31] M. Kuss-Petermann, O. S. Wenger, J. Phys. Chem. A 2013, 117, 5726.

[32] J. M. Mayer, Annu. Rev. Phys. Chem. 2004, 55, 363.

[33] I. Kaljurand, A. Kütt, L. Soovali, T. Rodima, V. Maemets, I. Leito, I. A. Koppel, J. Org. Chem. 2005, 70, 1019.

[34] Note that this is not a matter of temporal resolution of the used equipment. It is easily possible to decelerate the overall reaction to rates well below $10^{8} \mathrm{~s}^{-1}$ by using lower pyrrolidine concentrations. The intermediate remains undetectable under such conditions.

[35] O. S. Wenger, Chem. Soc. Rev. 2011, 40, 3538.

[36] E. A. Weiss, M. J. Ahrens, L. E. Sinks, A. V. Gusev, M. A. Ratner, M. R. Wasielewski, J. Am. Chem. Soc. 2004, 126, 5577.

[37] T. Irebo, O. Johansson, L. Hammarström, J. Am. Chem. Soc. 2008, $130,9194$.

[38] A. Magnuson, H. Berglund, P. Korall, L. Hammarström, B. Åkermark, S. Styring, L. C. Sun, J. Am. Chem. Soc. 1997, 119, 10720 .

[39] M.-T. Zhang, T. Irebo, O. Johansson, L. Hammarström, J. Am. Chem. Soc. 2011, 133, 13224.

[40] L. Biczok, N. Gupta, H. Linschitz, J. Am. Chem. Soc. 1997, 119, 12601.

[41] L. Biczók, H. Linschitz, J. Phys. Chem. 1995, 99, 1843.

[42] I. J. Rhile, T. F. Markle, H. Nagao, A. G. DiPasquale, O. P. Lam, M. A. Lockwood, K. Rotter, J. M. Mayer, J. Am. Chem. Soc. 2006, 128,6075 .

[43] I. J. Rhile, J. M. Mayer, J. Am. Chem. Soc. 2004, 126, 12718.

[44] J. N. Schrauben, M. Cattaneo, T. C. Day, A. L. Tenderholt, J. M. Mayer, J. Am. Chem. Soc. 2012, 134, 16635.

[45] C. Costentin, M. Robert, J. M. Savéant, C. Tard, Angew. Chem. Int. Ed. 2010, 49, 3803.

[46] W. Herzog, C. Bronner, S. Löffler, B. C. He, D. Kratzert, D. Stalke, A. Hauser, O. S. Wenger, ChemPhysChem 2013, 14, 1168.

[47] P. Müller, K. Brettel, Photochem. Photobiol. Sci. 2012, 11, 632.

[48] J. J. Concepcion, M. K. Brennaman, J. R. Deyton, N. V. Lebedeva, M. D. E. Forbes, J. M. Papanikolas, T. J. Meyer, J. Am. Chem. Soc. 2007, 129, 6968.

[49] Error bars associated with such fits are unreasonably large.

[50] T. F. Markle, I. J. Rhile, J. M. Mayer, J. Am. Chem. Soc. 2011, $133,17341$.

[51] D. Hanss, O. S. Wenger, Inorg. Chem. 2008, 47, 9081.

[52] D. Hanss, O. S. Wenger, Inorg. Chem. 2009, 48, 671.

[53] M. T. Indelli, C. Chiorboli, L. Flamigni, L. De Cola, F. Scandola, Inorg. Chem. 2007, 46, 5630.

[54] B. Albinsson, M. P. Eng, K. Pettersson, M. U. Winters, Phys. Chem. Chem. Phys. 2007, 9, 5847.

[55] O. S. Wenger, Acc. Chem. Res. 2011, 44, 25.

Received: ((will be filled in by the editorial staff))

Revised: ((will be filled in by the editorial staff)) Published online: ((will be filled in by the editorial staff)) 
[a] Dr. Jing Chen, ${ }^{\dagger}$ Martin Kuss-Petermann, ${ }^{\dagger}$ Prof. Dr. Oliver S. Wenger Department of Chemistry

University of Basel

Spitalstrasse 51, CH-4056 Basel, Switzerland

Fax: (+) 41612670976

E-mail: oliver.wenger@unibas.ch

${ }^{\dagger}$ These two authors contributed equally.

Supporting information for this article is available on the WWW under http://www.chemeurj.org/ or from the author. 


\section{Entry for the Table of Contents}

\section{Layout 1:}

Proton-coupled electron transfer

Jing Chen, Martin Kuss-Petermann, Oliver S. Wenger* Page

- Page

Distance Dependence of Bidirectional Concerted Proton-

Electron Transfer in PhenolRu(2,2'-bipyridine $)_{3}{ }^{2+}$ Dyads
The dependence of the rates for bidirectional concerted protonelectron transfer (CPET) on the electron donor - electron acceptor distance was determined for the first time. The results are relevant in the context of photo-driven separation of protons and electrons across natural or artificial membranes as a means of light-to-chemical energy conversion. 